WHAT CHARACTERIZES LEADING COMPANIES WITHIN BUSINESS EXCELLENCE MODELS? AN ANALYSIS OF "EFQM RECOGNIZED FOR EXCELLENCE" RECIPIENTS IN SPAIN

\author{
Ana B. Escrig* \\ Department of Business Administration and Marketing \\ Universitat Jaume I, Castellón, Spain \\ Lilian M. de Menezes \\ Faculty of Management \\ Cass Business School, City University London, London, UK
}

* Corresponding author:

Ana B. Escrig (escrigt@uji.es)

Department of Business Administration and Marketing

Universitat Jaume I

Avd. Sos Baynat s/n, 12071

Castellón, Spain

Tel.: 34964728536

Fax: 34964728529.

E-mail addresses:

escrigt@uji.es (A.B. Escrig)

1.deMenezes@city.ac.uk (L.M. de Menezes) 


\title{
WHAT CHARACTERIZES LEADING COMPANIES WITHIN BUSINESS EXCELLENCE MODELS? AN ANALYSIS OF "EFQM RECOGNIZED FOR EXCELLENCE" RECIPIENTS IN SPAIN
}

\begin{abstract}
This paper investigates whether there is a specific approach to the adoption of best management practices embedded in the EFQM Excellence Model, which characterizes leading "Recognized for Excellence" organizations in Spain. In addition, it studies which practices within EFQM's enablers predict high performance. In contrast to most previous research that used surveys of managers' perceptions, this study uses the actual criteria and sub-criteria scores attained by organizations in their assessment for EFQM recognition. Scores of a population of 216 organizations, which were assessed in the period from March 2011 to March 2013, are analyzed via ANOVA, factor and regression analyses. The findings show that Spanish organizations adopt the best practices encompassing the EFQM model in a similar fashion: organizations on average follow parallel trends in the scores received per criterion, and there are no significant differences in the importance attributed to enablers. Either role models are being followed, or most organizations know what is expected by the assessors and try to fulfil these expectations. Consequently, an imitative process disseminates and legitimizes the EFQM model in Spain. In addition, it is found that the People criterion makes a difference in attaining high performance, thus emphasizing the relative importance of the softer dimension in Quality Management. This study contributes to the management literature on best practices, by highlighting a consistent trend in the use of the EFQM model, and also provides insights to managers on how to better allocate resources within Business Excellence Models.
\end{abstract}

Keywords: EFQM Excellence Model, enablers, results, high performance, leading organizations, approaches to best practices.

\section{Introduction}

A growing stream of research highlights the importance of adopting management practices that have been successful in leading organizations. Their basic assumption is that the adoption of what are thought to be best management practices will lead to superior performance and competitive advantage (Voss, 1995, 2005; Davies and Kochhar, 2002; Leseure et al., 2004, Laugen et al., 2005; Kalchschmidt, 2012; Prester, 2013; Alwazae et al., 2014). As Xu and Yeh (2012) define, best practices are techniques, methods, processes, activities, or mechanisms implemented in order to optimize performance and to minimize the possibility of mistakes. With the emergence of quality management awards, and more specifically the Malcolm Baldrige National Quality Award (MBNQA) and the European Foundation for Quality Management (EFQM) Excellence Award, the adoption of best practices and their link with performance achieved greater prominence (Voss, 1995, 2005). The Business Excellence Models (BEMs) underlying these awards embody both the adoption of a collection of what have been widely acknowledged to be best practices and the measurement of stakeholder-related performance results. Consequently, as Mohammad et al. (2011) argued, BEMs are overarching frameworks for managing and/or aligning multiple improvement initiatives. A comprehensive range 
of best practices and managerial orientations are implicit in the enablers criteria included in BEMs, thus implying that combinations of best practices should be in place in organizations that are recognized or accredited by BEMs (Alwazae et al., 2014).

The existing BEMs have, in most cases, targeted the dissemination of the principles and methods of Quality Management (QM) and business excellence, and have been supported by national bodies as a basis for award programs (Dahlgaard et al., 2013). More than 80 national and state/regional BEMs, as well as awards worldwide, are inspired by either the MBNQA or the EFQM Award criteria, and in 2011 there were approximately 100 national BEMs in use (Mann et al., 2011; Talwar, 2011). Many organizations have therefore adopted a BEM, because generally BEMs promote best practices and are tools for self-assessment, benchmarking and, most importantly within a QM perspective, they facilitate continuous improvement. In short, BEMs are seen as practically useful.

The general practitioner interest in BEMs has motivated a stream of academic research on their implementation and outcomes. Several studies (e.g. Hendricks and Singhal, 2001; Corredor and Goñi, 2011; Boulter et al., 2013) have assessed the link between QM implementation and performance by focusing on award winners. For example, Hendricks and Singhal (2001), in their study of the link QM-performance, assumed that award winners had effectively implemented QM. Nevertheless, the specific research on BEMs as a framework for QM implementation has been mainly centered on the relationships between the categories in the BEMs that define operations, and those that define results. Hence, the core intent of this stream of research is to test the validity of the theoretical model underlying BEMs. Accordingly, recent studies, such as Bou et al. (2009) and Heras et al. (2012), which focused on the EFQM Excellence Model, or He et al. (2011) and Karimi et al. (2014) on the MBNQA, supported the hypothesis that excellent management of enablers criteria (those that define operations) leads to excellence in results.

In spite of several inferences of a positive correlation between practices and results, which confirmed the internal structure of BEMs, some authors questioned the positive association between their use and performance. For example, in the particular case of Spain that is the context of the present study, Corredor and Goñi (2011) noted that the fact of gaining a quality award does not invariably lead to performance gains. Similarly, Gómez et al. (2011) concluded that some EFQM enablers do not have significant effect on results and that the model does not behave according to its definition by the EFQM. More broadly, Voss $(1995,2005)$, while focusing on best practices, and Doeleman et al. (2014), in the context of reviewing the empirical research on the adoption of the EFQM Excellence Model, warned that best practices may not on their own guarantee improvements in performance. Both studies observed that there is a substantial failure rate in the implementation of such practices. Consequently, there is a need to investigate how leading organizations (those that have achieved a high level of practice and performance) adopt BEMs. Moreover, by identifying differences in the way organizations approach the model, one may clarify why some organizations fall behind while others excel, and therefore provide insights or practical guidelines on how best to approach BEMs.

The literature on how leading organizations may distinguish themselves from the rest is thus far inconclusive. The QM literature argues for an integrated use of best practices (de Menezes et al., 2010), and some authors hypothesized synergistic effects (Shah and Ward, 2003) between practices when an organization is a high-performer (Hackman and Wageman, 1995; Zu et al., 2010; Zairi and Alsughayir, 2011). Potential synergies and integration, in line with Shah and Ward's (2003) conclusions, might imply a holistic 
adoption of all the best practices embedded in a BEM. However, Wu and Zhang (2013) in an analysis of explorative and exploitative quality management practices showed that, while firms can benefit from QM practices with both types of orientations, they may emphasize one orientation over the other. In a similar vein, several authors (Williams et al., 2006; Gómez et al., 2011; Sampaio et al., 2012; Asif and Gouthier, 2014) have highlighted that the EFQM model is not prescriptive, and therefore does not require the use of specific practices. Consequently, multiple approaches or different ways of adopting the EFQM model may be expected, since organizations can in principle achieve high levels of excellence by excelling in some criteria, even though they are rated poorly on others. In the same line of reasoning, the resource-based view of the firm would argue that special configurations of practice use are what should lead to competitive advantage. Indeed, some studies (e.g. Lu et al., 2011; Fan and Lu, 2014) stressed the critical importance of organizations having an individualistic logic (individual unique practices) in the achievement of business excellence. Accordingly, questions arise regarding the way leading organizations achieve a high level of excellence, for example: is a high level of excellence associated with using all practices well and excelling in all criteria? Or, is it simply about focusing on those practices that best fit an organization's idiosyncrasies?

In this context, the purpose of the present study is to investigate what makes a leading company within the EFQM Excellence Model. More specifically, this paper reports an analysis of a population of organizations that have been awarded the "Recognized for Excellence" status in Spain. Its first goal is to explore whether those organizations that were accredited at the highest level in the assessment have any specific approach to the adoption of the best practices, which are embedded in the enablers criteria of the EFQM model. Secondly, it aims to unveil which best practices within the enablers criteria may predict being a high performing organization, in order to make explicit the array of best practices an organization should be more likely to emphasize in its path towards being recognized for excellence.

A fundamental question for managers and academics is how organizations achieve and sustain competitive advantage in their pursuit of business excellence. As stated by Dahlgaard et al. (2013), BEMs have the double purpose of conducting an assessment of organization's performance as well as guiding it towards business excellence. An analysis of leading companies can unveil how organizations should manage their use of BEMs, thus reducing the likelihood that they make inadequate decisions concerning which practices to focus. Such analysis would also contribute to narrowing the gap in the literature, as identified by Araújo and Sampaio (2014), concerning the lack of awareness about the approaches or methods that an organization needs to develop in its improvement path. In doing so, this study adds to the best practice literature and the scientific assessment of the EFQM Excellence Model that, as Williams et al. (2006) and Heras et al. (2012) highlighted, is critical for the legitimization of any management model.

This article is structured as follows. In the next section, we review previous literature on approaches to the EFQM Excellence Model, including the assumption of a causal relationship between practices and results within the model, and set our research questions. Section 3 describes the methodology. Finally, sections 4, 5 and 6 present the results of the empirical study, its main implications and conclusions. 


\section{Literature Review and Research Questions}

\subsection{The EFQM Excellence Model and its Levels of excellence}

The EFQM Excellence Model is the most extensively used BEM in Europe. The model reflects the premises and the set of QM constructs, which are most frequently used in the literature (Sousa and Voss, 2002; Bou et al., 2009; Corredor and Goñi, 2011). Consequently, the EFQM model can also be analyzed from the perspective of the broader QM literature.

The EFQM was launched in 1991 as a non-prescriptive framework based on nine criteria, whose present version and respective weights are depicted in Figure 1. Each criterion encompasses several sub-criteria, thus leading to a total of 32 sub-criteria that are listed in the Appendix. The EFQM model was last revised in 2013 with the aim to align the framework with current business needs and trends. Yet, the most recent fundamental change in the model took place in 2010, when the weights were reviewed in order to achieve a more balanced weighting scheme. This revision gave an 'equal' value to an organization's capacity and best practices, through the 5 enablers criteria, and the performance it delivers for all stakeholders, via the 4 results criteria (both Enablers and Results are kept at 50\%, as follows from Figure 1 when weights on each side are added).

Figure 1. The EFQM Excellence Model

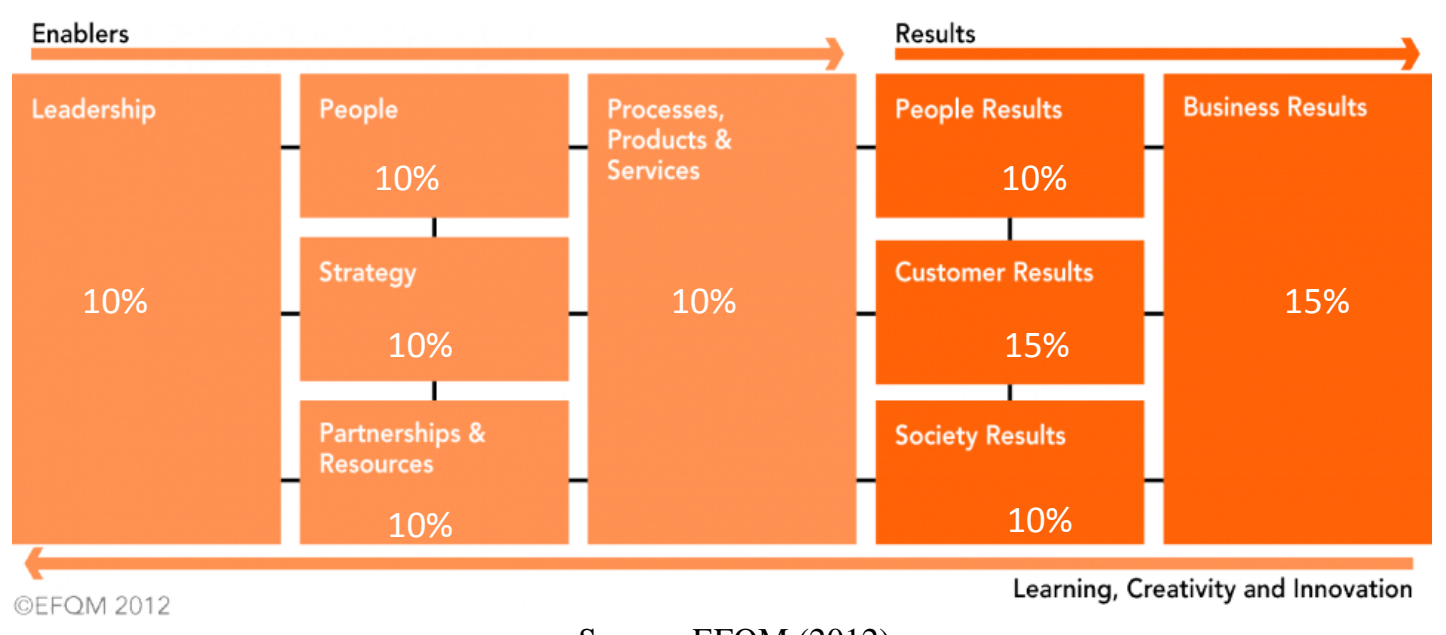

Source: EFQM (2012)

Some scholars (e.g. Eskildsen et al., 2001; Williams et al., 2006; Bou et al., 2009; Calvo et al., 2014) have highlighted the complex structure in the EFQM criteria, where changes in one element can be related to changes in other elements, thus implying interdependence between components. Furthermore, the model assumes a causal relationship between enablers and results, since it is based on the premise that excellent results in key stakeholders are achieved through excellence in enablers, i.e.: having strong leadership and clear strategic direction, developing and improving people, establishing partnerships and processes to deliver value-adding products and services to customers (EFQM, 2012). Hence, it could be inferred that being recognized for excellence implies having achieved both enablers excellence and results excellence. Enablers and results excellences have been conceptualized in empirical studies as single constructs (e.g. Curkovic et al., 2000; Bou et al., 2009; Sadikoglu and Zehir, 2010). Taking into account this conceptualization, enablers excellence can be interpreted as the overall approach that organizations adopt when they implement best practices within the model, which should be reflected in the 
score achieved in each of the enablers criteria. In turn, results excellence encompasses the satisfaction of stakeholders' needs, and should be reflected in the scores achieved in each results criterion. Different levels of excellence can then be established depending on how organizations score in the enablers and the results criteria.

In fact, a scheme of recognition of the level of excellence was launched by the EFQM ("Recognized for Excellence"), encouraging organizations to be recognized through an external assessment based on the EFQM Excellence Model. As Grigg and Mann (2008) and Jayamaha et al. (2009) explain, when an organization applies for specific levels in the recognition scheme, its practices are then assessed against the model; points are allocated to each sub-criterion by a panel of trained assessors using a scoring guideline based on evidence of actual performance. In this process, the 32 sub-criteria need to be evaluated in order to determine the organizations' final score. Accordingly, accreditation can be at three levels (5-star, 4-star or 3-star) depending on the achieved scores. The recognition for excellence is then valid for two years, after which an organization would need to apply for reaccreditation. The level of excellence that is achieved depends on the breadth and depth of best practices that are in place, as well as the impact these practices have on performance. If an organization is accredited as a 5-star, it is therefore judged to be a leading organization.

\subsection{The adoption of the EFQM Excellence Model by leading organizations}

\section{Configuration of practices according to QM literature}

Although, as described above, some authors advocate the analysis of enablers and results as a whole system via the commonalities between all the elements in the EFQM model, other authors (e.g. Rusjan 2005; Sampaio et al., 2012; Asif and Gouthier, 2014) state that the EFQM suggests several approaches in the path towards excellence. In their view, by using the model, organizations can develop best practices in a coherent way but, at the same time, given the non-prescriptive nature of the model, organizations can develop their own "specific" approach. As Williams et al. (2006) warned, organizations do not need to score a minimum level in all the criteria in order to achieve organizational excellence, and thus they should be free to emphasize specific elements. Co-existing approaches to excellence are also consistent with the resource-based view of a firm (e.g., Barney, 1991; Grant, 1991). This organization adaptation perspective on how the model should be adopted further advocates that competitive advantage results from an organization's ability to exploit the inimitable characteristics of its pool of resources and capabilities. Consequently, the heterogeneity in resources between organizations would give rise to different combination of practices in the EFQM enablers criteria. Organizations would exploit their strengths, while adopting the EFQM framework, rather than take a universal approach that interprets the model as sets of rules that must be followed in the road towards excellence.

To the best of our knowledge no study of such potential combinations of EFQM criteria has been developed thus far, especially in Spain. Nonetheless, using a configurationtheoretic approach (e.g. Meyer et al., 1993; Short et al., 2008), different taxonomies for QM have been proposed in the literature (see Table 1), based on which distinct approaches to the adoption of the best practices in the EFQM model can be inferred. In general, as summarized in Table 1, the studies seem to agree that the different patterns of adoption of QM practices represent different degrees of QM development, as indicated in the fourth column in the table (Configurations). Up to six different approaches or levels of QM were 
identified. However, as Dale and Lascelles (1997: 418) warned, they "are not necessarily the stages which organizations pass on their TQM journey, rather they are characteristics and behavior which organizations display in relation to TQM at one point in time". Moreover, from the summaries in the last column of Table 1, one can infer that the configurations that were found to be associated with superior performance are those that exhibit a high level in all the QM practices and assume complementarities in practice use. It is noteworthy that among these studies, only Zhao et al. (2004) concluded that organizations can achieve similar effective business results by focusing on different elements of QM so that a high performing organization may not necessarily have to do well in all areas of QM.

Table 1. Taxonomies of QM practices in the literature

\begin{tabular}{|c|c|c|c|c|}
\hline Authors & Purpose of the study & Methodology & Configurations & $\begin{array}{c}\text { Relationship with } \\
\text { performance }\end{array}$ \\
\hline $\begin{array}{l}\text { Dale and } \\
\text { Lascelles } \\
(1997)\end{array}$ & $\begin{array}{l}\text { To state different levels } \\
\text { of QM adoption, that } \\
\text { could be used as a } \\
\text { benchmark to } \\
\text { characterize } \\
\text { organizations and help } \\
\text { them to recognize the } \\
\text { issues to which } \\
\text { attention needs to be } \\
\text { given. }\end{array}$ & $\begin{array}{l}\text { Empirical } \\
\text { observation }\end{array}$ & $\begin{array}{l}\text { Six Levels of QM } \\
\text { adoption: } \\
\text { Uncommitted } \\
\text { Drifters } \\
\text { Tool pushers } \\
\text { Improvers } \\
\text { Award winners } \\
\text { World-class }\end{array}$ & $\begin{array}{l}\text { "Improvers" is the level } \\
\text { where QM begins to have a } \\
\text { real impact on performance. } \\
\text { In lower levels, QM is not } \\
\text { internalized throughout the } \\
\text { organization, and an overall } \\
\text { strategy which pulls all the } \\
\text { improvement together is not } \\
\text { in place. }\end{array}$ \\
\hline $\begin{array}{l}\text { Chin and } \\
\text { Pun } \\
(2002)\end{array}$ & $\begin{array}{l}\text { To develop a scoring } \\
\text { scheme to assist } \\
\text { companies in assessing } \\
\text { their QM } \\
\text { implementation status. }\end{array}$ & $\begin{array}{l}\text { In-depth case } \\
\text { studies among } \\
\text { six Chinese } \\
\text { companies }\end{array}$ & $\begin{array}{l}\text { Five levels of QM } \\
\text { status: } \\
\text { Unaware } \\
\text { Uncommitted } \\
\text { Initiator } \\
\text { Improver } \\
\text { Achiever } \\
\end{array}$ & $\begin{array}{l}\text { Like Dale and Lascelles's } \\
\text { (1997) levels, the more } \\
\text { developed status implies a } \\
\text { depth in the integration of } \\
\text { QM practices throughout } \\
\text { the organization. }\end{array}$ \\
\hline $\begin{array}{l}\text { Yeung et } \\
\text { al. (2003) }\end{array}$ & $\begin{array}{l}\text { To investigate the } \\
\text { existence of different } \\
\text { patterns of quality } \\
\text { management systems } \\
\text { (QMS) and establish } \\
\text { their relationship with } \\
\text { performance. }\end{array}$ & $\begin{array}{l}\text { Quantitative and } \\
\text { qualitative study } \\
\text { of } 225 \\
\text { firms in the } \\
\text { electronics } \\
\text { industry in } \\
\text { Hong Kong. } \\
\text { Cluster analysis } \\
\text { of survey data } \\
\text { concerning QM } \\
\text { practices and } \\
\text { performance }\end{array}$ & $\begin{array}{l}\text { Four patterns of QMS: } \\
\text { Undeveloped QS } \\
\text { Frame QS } \\
\text { Accommodating QS } \\
\text { Strategic QS }\end{array}$ & $\begin{array}{l}\text { Overall performance can be } \\
\text { enhanced only by the } \\
\text { establishment of a Strategic } \\
\text { QS. } \\
\text { Authors state that further } \\
\text { development of a QMS } \\
\text { entails integration of } \\
\text { technical infrastructures and } \\
\text { social elements (the } \\
\text { sociotechnical system). }\end{array}$ \\
\hline $\begin{array}{l}\text { Zhao et } \\
\text { al. (2004) }\end{array}$ & $\begin{array}{l}\text { To explore patterns of } \\
\text { QM practices and } \\
\text { investigate contingent } \\
\text { relationships. }\end{array}$ & $\begin{array}{l}\text { Survey data } \\
\text { from } 145 \\
\text { service firms in } \\
\text { China. } \\
\text { Cluster analysis } \\
\text { of QM practices } \\
\text { and results } \\
\text { measured by } \\
\text { MBNQA }\end{array}$ & $\begin{array}{l}\text { Four patterns: } \\
\text { Undeveloped QS } \\
\text { Accommodating QS } \\
\text { Strategic QS } \\
\text { Soft QS }\end{array}$ & $\begin{array}{l}\text { Strategic QS and Soft QS } \\
\text { organizations outperformed } \\
\text { others and had high levels } \\
\text { of QM practices, but Soft } \\
\text { QS had virtually no process } \\
\text { management systems. } \\
\text { It is not necessary for a } \\
\text { company to do well in all } \\
\text { areas of QM to achieve a } \\
\text { good performance. }\end{array}$ \\
\hline $\begin{array}{l}\text { Ryan and } \\
\text { Moss } \\
(2005)\end{array}$ & $\begin{array}{l}\text { To determine the QM } \\
\text { practices of high } \\
\text { performing groups }\end{array}$ & $\begin{array}{l}\text { Random sample } \\
\text { of } 210 \text { SMEs } \\
\text { located in the } \\
\text { Southeastern } \\
\text { United States. } \\
\text { Cluster profiling }\end{array}$ & $\begin{array}{l}\text { Four groups of QM: } \\
\text { Nonadopters } \\
\text { Unfocused implementer } \\
\text { High implementer } \\
\text { Holistic implementer }\end{array}$ & $\begin{array}{l}\text { Holistic implementers, } \\
\text { which exhibit a high level } \\
\text { of QM practices and deploy } \\
\text { an integrated QM initiative, } \\
\text { perform better than the } \\
\text { other groups, which deploy } \\
\text { a selective and more } \\
\text { piecemeal QM adoption. }\end{array}$ \\
\hline
\end{tabular}




\begin{tabular}{|l|l|l|l|l|}
\hline $\begin{array}{l}\text { Lai et al. } \\
(2012)\end{array}$ & $\begin{array}{l}\text { To study whether } \\
\text { different configurations } \\
\text { of quality management } \\
\text { and marketing (Q\&M) } \\
\text { implementation exist } \\
\text { and their implications } \\
\text { for firm performance. }\end{array}$ & $\begin{array}{l}\text { Survey 304 } \\
\text { organizations } \\
\text { that have QM } \\
\text { systems in Hong } \\
\text { Kong, and in- } \\
\text { depth }\end{array}$ & $\begin{array}{l}\text { Three configurations: } \\
\text { Reactive firms } \\
\text { Prterviews. } \\
\text { Cluster analysis }\end{array}$ & $\begin{array}{l}\text { Proactive firms where } \\
\text { Q\&M are implemented at a } \\
\text { high level and in an }\end{array}$ \\
& & & $\begin{array}{l}\text { integrated way engender } \\
\text { better performance than the } \\
\text { other groups that show an } \\
\text { unbalanced implementation. }\end{array}$ \\
\hline
\end{tabular}

\section{Can Approaches to EFQM enablers discriminate organizations?}

The analysis of the different taxonomies, as summarized in Table 1, shows that a systemic approach is common to the configurations that the authors associated with high performance. For example, Ryan and Moss (2005) named "holistic implementers" those organizations that perform better than other groups. Moreover, Yeung et al. (2003) described high performers as organizations that take together elements of different nature (technical and social), thus adopting a systemic approach. In a similar vein, Lai et al. (2012) concluded that when QM practices are implemented in an integrated way and at a high level, better performance is achieved. Consequently, based on this stream of literature, leading organizations in the EFQM model would be expected to embrace all enablers criteria at a high level of implementation. Indeed, management thought has long advocated such an all-inclusive approach to change, in contrast to a piecemeal adoption of practices. Concepts such as integrated manufacturing, lean production and world-class manufacturing, which date as back as the 1970s and came to the fore in the 1990s, have stressed the importance of a comprehensive integrated system. This expectation is also supported in previous empirical studies in Operations Management. For example, GarcíaBernal et al. (2004) found that EFQM enablers show complementarities among themselves and suggest a global adoption of the model if better results want to be achieved. Abdullah's (2010), de Menezes et al. (2010) and Phan et al. (2011) also concluded that the highest level of QM implementation is achieved through mutual supportive relationships among practices. In fact, Karimi et al. (2014), in a study of the MBNQA, observed that successful companies need to be aware that concentrating on specific sections of the BEM will not be sufficient for attaining a high level of performance. In order to be effective, therefore, all the enablers should be interrelated, thus shaping what Jayaram et al. (2010) called "a socio-technical mix" of practices. Given that the EFQM model embodies hard and soft practices (Williams, 2006; Bou et al., 2009; Calvo-Mora et al., 2014), both types of practices would need to be in place in order to achieve high performance. As Williams et al. (2006) stated, what has a real value is not a practice per se, but rather its combined use with other practices. That is, to achieve effective results, organizations need to effectively employ the skills of employees (people), but also other factors: a good leadership and an effective strategy to keep people focused on the mission with a high dose of enthusiasm; resources and processes, which must be related to the strategy, measured and improved to ultimately provide the desired results. As all these factors need to coexist, according to EFQM, leading organizations are expected to equally value them.

Following the above considerations, further questions arise: Is an integrated adoption of best practices specific to leading organizations? Do organizations at lower levels of performance exhibit other combinations of EFQM criteria? In an attempt to answer these questions, we refer to the literature summarized in Table 1. Given the findings of Ryan and Moss's (2005) and Lai et al.'s (2012), it appears that lower performers would be prone to focus on specific criteria in the EFQM model and emphasize particular practices. 
As a matter of fact, Ryan and Moss (2005) labelled "unfocussed" those QM adopters that are yet to achieve a high level of performance and that exhibit a more piecemeal QM adoption. In addition, Lai et al. (2012) concluded that low performers exhibit an unbalanced implementation. Moreover, Dale and Lascelles (1997) and Yeung et al. (2003) appeared to be in agreement with this interpretation, since they described that in lower levels of QM implementation the priority is given to firefighting, where organizations lack focus in their QM efforts and pick and choose their initiatives.

In addition to the studies that are summarized in Table 1, Mohammad et al. (2011) also suggested that organizations select the most appropriate improvement initiatives by narrowing down the options according to the areas of implementation (areas within the different enablers) and level of business excellence. The authors also argued that, if an organization is yet to achieve a high level of excellence, it can target specific initiatives to tackle the "low hanging fruits". However, they also stated that when an organization's business excellence increases and all its QM initiatives are aligned, integrated and fitted within the organization, the organization reaches a stage where it has become a unique model of success. Different emphases could stem from constraints in resources, regulation that may be specific to an industrial sector, or simply reflect how organizations align their strategic objectives to managing their operations. In addition, the adoption of less costly practices or more convenient substitutes is more commonly observed in laggard organizations. In line with the broader operations management literature, the existence of different approaches to BEMs that vary with the achieved excellence level is consistent with the model proposed by Hayes and Wheelwright (1984), which focuses on how operations contribute to the organization. This model traces the progression of the operations function from an initial stage, where operations are centered on correcting problems, to more advanced stages where integration with strategy, and performance objectives, is gradually observed. These expectations motivate our first research question:

RQ1: Do leading companies show a different approach to the adoption of enabler criteria when compared to those organizations that exhibit lower excellence levels?

\section{EFQM enablers criteria and high performance}

The former research question addresses potential differences in the way leading organizations behave in the EFQM enablers criteria, with regard to other organizations. Our next interest is in investigating which practices in the enablers criteria are more likely to produce high stakeholder-related performance results.

The causal relationship between enablers and results, which is implicit in the EFQM model, has been analyzed in previous research (e.g. Eskildsen et al., 2004; Bou et al., 2009; Nazemi, 2010; Gómez et al., 2011; Heras et al., 2012; Calvo et al., 2014). However, their findings concerning this expected causal relationship seem to be inconclusive. Bou et al. (2009) concluded that enablers criteria must be considered together to have a real impact on the result criteria. In the same vein, Nazemi (2010) found no relationship between specific enablers criteria and the results criteria, and advocate that a combined enabling factor is supposed to affect results. Gómez et al. (2011), however, warned that not all the best practices embedded in the EFQM criteria have been found to have a significant and equal influence on the results. Furthermore, in the QM academic literature some authors have also concluded that certain QM practices are the most significant predictors of performance. For example, Samson and Terziovski (1999) found that soft QM practices, related to leadership, management of people and customer focus were the 
strongest significant predictors of operational performance. Merino (2003) also stressed the role of human resource practices, together with product design and development, in the improvement of performance. For their part, Psomas and Fotopoulos (2010) concluded that the main significant predictors of quality improvement were QM practices related to top management, and process and data quality management.

Although one would expect an equal importance to be attributed to all enablers in order to improve results since EFQM gives equal weight to each enabler (as reproduced in Figure 1), previous research (e.g. Eskildsen et al., 2001, 2002; Williams et al., 2006; Nazemi, 2010) have stressed that such a weighting scheme is not empirically supported, and might not correspond with the way organizations adopt best practices. Likewise, as discussed above, there may be organizations that emphasize some enabler criteria over others in their path toward excellence. In fact, Dahlgaard et al. (2013), in their description of the journey towards excellence, reported that the weight or focus an organization gives to each criterion varies from company to company depending on their context. Hence, different emphases in enablers may be linked to different results.

Moreover, Corbett and Angell (2011), while analyzing how organizations that repeat applications in New Zealand Business Excellence Awards improve their scores, observed that applicants are able to improve their scores on the enablers categories at a much faster rate than on the results scores. Hence, the authors' conclusions suggest that an improvement in enablers is not always, nor at least in the short range, followed by an improvement in results. This raises a question concerning which enablers really make a difference in attaining best results. In this context, the second research question in this study is therefore:

RQ2: Which enablers criteria best predict high stakeholder-related performance results in the EFQM model?

\section{Methodology}

\subsection{Data}

The present study is based on the population of 216 Spanish organizations that in March 2013 had a validated recognition in the "Recognized for Excellence" EFQM scheme by the $\mathrm{CEG}^{1}$. We examined the scores obtained by organizations in their external assessments made by independent professionals using the very rigorous protocol of the EFQM model. In the process to obtain such recognition, organizations undergo an exhaustive assessment process, which typically involves scrutinizing records, meetings with senior managers and their subordinates, and even actual observations of key processes (Grigg \& Mann, 2008; Jayamaha et al. 2009). The independent assessors, who belong to the CEG, receive specialist formal training in the EFQM self-assessment model and are committed to improving the management quality of organizations. As noted by several authors - e.g. Pannirselvam \& Ferguson (2001) and Jayamaha et al. (2011) in the case of Malcolm Baldrige model, as well as Gómez et al. (2011) and Heras et al.(2012) with regard to the EFQM model - , data obtained from external assessment processes are reliable sources of information.

The database covers the scores on all criteria and sub-criteria of the EFQM model attained for each organization, as well as its final score, which results from the weighted

\footnotetext{
${ }^{1}$ CEG (Club Excelencia en Gestión), which is the EFQM's partner in Spain.
} 
aggregation of criterion scores, using a range from 0 to 100. Although individual organizations in the database cannot be identified because of a confidentiality agreement with CEG, it is noteworthy that they represent different industry sectors, namely: manufacturing, service, healthcare, education, and non-profit. They are also located in different geographical regions in Spain, and their distribution by size is such as follows: less than 50 employees: 44; between 50 and 249 employees: 87; 250 and more employees: 85 .

\subsection{Data analysis and measures}

Inspired by Laugen et al. (2005), the data are analyzed in three stages. First, the statistical distribution and correlations of the scores were analyzed. Second, in order to tackle our first research question (RQ1), leading organizations need to be identified in the data. One variable in the dataset accounts for the recognition level an organization has achieved (3star, 4-star or 5-star), and has been used to measure the level of excellence and differentiate leading organizations (5-star) from others ${ }^{2}$. A 5-star level is reached when the organization has a score (weighted aggregation of the scores in each criterion) greater than 500 points. The EFQM defines these organizations as high performing organizations, "where change is the norm and who improve, refine and simplify the practices they use to achieve their goals, and at the same time have ongoing results in the line with their strategy" (http://www.efqm.org/what-we-do/recognition/efqm-recognised-forexcellence). In short, they are organizations that excel in enablers and results. A preliminary analysis of the distributions of sub-criteria scores in each level and a comparison between levels was undertaken. By using boxplots, outliers were identified. Medians and variances between levels were tested, and normality was assessed. Subsequently, following the procedure used by Prajogo and Sohal (2004) and Laugen et al. (2005), differences in the adoption of best practices (enablers criteria) between leading companies (5-star) and the other accredited organizations at lower levels (3 and 4-star) were examined via analysis of variance (ANOVA). In addition, a multi-sample factorial analysis was estimated in order to examine specific differences between groups.

Finally, a regression model is estimated, in order to find which best practices may predict that an organization can be a high performer in the results criteria. High performing organizations are measured by a binary indicator, which is equal to " 1 " when their aggregated weighted score on results criteria are in the top quartile of the overall results distribution, and "0" otherwise (Phan et al., 2011). Given the binary dependent variable that follows from the second research question, a logistic regression model was chosen. The dependent variable is whether the organization is a high performer in results criteria, the independent variables are the scores on enablers criteria ${ }^{3}$, and the control variables are described below.

Given previous literature and the information in the dataset, controls are included in the regression model. First, size has been identified as a specific characteristic that can influence results in the context of QM (Hendricks and Singhal, 2001; Zhao et al., 2004;

\footnotetext{
${ }^{2}$ EFQM grants the excellence level depending on the final score each organization has attained in the external assessment process, which is calculated as the weighted aggregation of the scores in each of the nine criteria; 1000 is the maximum possible score. We have validated this measure of the excellence level through a factorial analysis of the actual sub-criteria scores in the database. Accordingly, we estimated a factor for enabler excellence and another factor for result excellence. We found that organizations with 5star recognition belong to the top quartile of the distribution of both factors.

3 Previous studies (e.g. Jayamaha et al., 2009; Gómez et al., 2011; Heras et al., 2012) have used the scores assigned by external assessors as a measure of the level an organization has in each criterion.
} 
Roca et al., 2006; Jayaram et al., 2010). In the regression model, it is measured as dummy variables representing different intervals: Size 1: $<50$ employees; Size 2: between 50 and 249; Size 3: > 250 employees. The reference category is large organizations (Size 3: > 250 employees). Another control variable is the region where the organization is located. The dataset also has information on whether organizations could be under the umbrella of regional excellence centers that are part of the national association of excellence centers, which is known as "cex" (Centros de Excelencia; Excellence Centers). These regional centers promote and support the different stages towards business excellence, and several scholars (e.g. Heras et al. 2006) argue that these centers are institutional agents in the process of disseminating and legitimizing QM practices. Hence, in the model, we contemplate this possible effect by controlling for the presence of a center of excellence in the area where the organization is based. This is done by means of a dummy variable that represent whether or not the region has an organization that belongs to the "cex". A final variable is introduced to control for this institutionalization role that other organizations play. It is a binary indicator of membership to the CEG, which is the EFQM's partner in Spain and whose mission includes the promotion of management excellence.

\section{Results}

\subsection{Preliminary analysis of the data}

The data were screened for outliers and the sample has 214 of the original 216 organizations. Table 2 shows descriptive statistics for the enablers and results criteria.

Table 2. Descriptive statistics and correlations $(\mathrm{N}=214)$

\begin{tabular}{|c|c|c|c|c|c|c|c|c|c|c|c|c|c|}
\hline Variable & Min. & Max. & Mean & S.D. & $\mathrm{C} 1$ & $\mathrm{C} 2$ & $\mathrm{C} 3$ & $\mathrm{C} 4$ & $\mathrm{C} 5$ & C6 & $\mathrm{C} 7$ & $\mathrm{C} 8$ & C9 \\
\hline $\mathrm{C} 1$ & 25.50 & 62.00 & 42.43 & 7.98 & 1 & & & & & & & & \\
\hline $\mathrm{C} 2$ & 23.75 & 66.25 & 42.84 & 8.73 & $0.865 * *$ & 1 & & & & & & & \\
\hline $\mathrm{C} 3$ & 25.22 & 62.25 & 40.83 & 7.76 & $0.856^{* *}$ & $0.807 * *$ & 1 & & & & & & \\
\hline $\mathrm{C} 4$ & 25.50 & 65.50 & 43.37 & 7.99 & $0.803 * *$ & $0.779 * *$ & $0.831 * *$ & 1 & & & & & \\
\hline C5 & 25.33 & 67.75 & 45.55 & 8.21 & $0.828 * *$ & $0.810 * *$ & $0.815^{* *}$ & $0.796 * *$ & 1 & & & & \\
\hline C6 & 20.00 & 68.75 & 42.85 & 9.28 & $0.699 * *$ & $0.722 * *$ & $0.680 * *$ & $0.688 * *$ & $0.724 * *$ & 1 & & & \\
\hline C7 & 11.25 & 60.00 & 37.56 & 9.75 & $0.676^{* *}$ & $0.638 * *$ & $0.707 * *$ & $0.542 * *$ & $0.590 * *$ & $0.684 * *$ & 1 & & \\
\hline $\mathrm{C} 8$ & 10.00 & 64.38 & 31.10 & 10.81 & $0.613 * *$ & $0.600 * *$ & $0.681 * *$ & $0.645^{* *}$ & $0.598 * *$ & $0.607 * *$ & $0.652^{* *}$ & 1 & \\
\hline C9 & 20.00 & 73.13 & 41.82 & 10.15 & $0.668 * *$ & $0.696 * *$ & $0.633^{* *}$ & $0.700 * *$ & $0.674 * *$ & $0.728 * *$ & $0.623^{* *}$ & $0.638^{* *}$ & 1 \\
\hline
\end{tabular}

More mechanistic practices, which are reflected in partnerships, resources (C4) and processes, products and services (C5) exhibit higher mean score when compared to management and people criteria. Society results (C8) and people results (C7) are the criteria that exhibit significant lower mean values as well as lower correlations with other criteria. This is consistent with previous studies of the EFQM model in Spain (Gómez et al., 2011; Heras et al., 2012).

As exhibited in Table 2, the positive high correlations within the enabler's and result's domains confirm the interrelationship and the expectation that in practice there are complementarities between the criteria in each of the two blocks in the EFQM model. The strong and positive correlations between enablers and results criteria also confirm the expected association between the two types of criteria. Overall, these observations are in line with previous analysis of the EFQM model (e.g. Bou et al, 2009; Calvo-Mora et al., 2014). Moreover, the high correlation in enablers (greater than 0.7) also suggests an 
underlying common factor in the adoption of best practices rather than clusters or a discrete latent space, which were identified in the QM literature that has been summarized in Table 1.

Considering that the dataset consists of different sized organizations located in distinct regions, the association between the corresponding variables and the level of excellence attained by an organization was examined. A cross-tabulation of level of excellence by size shows a positive association (Chi-square $=16.19 ; 4$ d.f.; $\mathrm{p}<0.01$ ): large organizations are more likely to reach a higher level of excellence (see upper side of Table 3). Most of the 39 organizations awarded a 5-star recognition are large, whereas most of the 74 organization awarded a 3-star recognition are small or medium sized organizations. Likewise, regarding location, although the strength is lower than in the case of size, there is association with the level of excellence (Chi-square=6.729; 2 d.f.; $p<0.05$ ): organizations located in a region where "cex" is not established are more likely to attain a lower level of excellence (see bottom of Table 3).

Table 3. Level of excellence by size and location

\begin{tabular}{llllll} 
& & \multicolumn{4}{c}{ Level of excellence } \\
\cline { 3 - 6 } & & 5-star & 4-star & 3-star & Total \\
\hline \multirow{3}{*}{ Size } & Small & 2 & 21 & 21 & 44 \\
& Medium & 12 & 46 & 29 & 87 \\
& Large & 25 & 34 & 24 & 83 \\
\hline \multirow{2}{*}{ Location } & Region in cex & 27 & 85 & 51 & 163 \\
& Region not in cex & 12 & 16 & 23 & 51 \\
\hline & Total & 39 & 101 & 74 & 214 \\
\hline
\end{tabular}

An analysis of the distribution scores of sub-criteria in each excellence level, by means of boxplots, suggested a similarity in the distributions of each sub-criterion in the 3 groups. It is noteworthy that while at the higher level-5-star-outliers where found among a few results sub-criteria that indicated exceptionally high performance, at the lower level, outliers were generally among enablers sub-criteria. Moreover, the few outliers that indicated emphasis being placed on a sub-criterion at the expense of another were observed at the lower levels. Together the fewer outliers and lower variance that were observed at the higher level confirm the expectation that organizations with 5-star recognition have a better understanding of the EFQM model.

\subsection{On leading organizations' adoption of enablers}

The first research question addresses whether leading organizations have a different approach to the enablers sub-criteria of the EFQM model when compared to other recognized organizations. In order to address this question, the combination of subcriteria (i.e. having higher scores on specific sub-criteria more than on others) were compared between leading organizations - 39 organizations that achieved a score greater than 500 in the assessment process-, and the other 175 organizations in the population, of which 101 achieved 4-star recognition and 74 achieved 3-star recognition. The mean scores for the 32 enablers sub-criteria in each level of excellence were calculated. They are plotted in Figure 2 and summarized in Table 4 together with their standard error and median scores. Significant differences in the mean scores of sub-criteria between the three levels of excellence were confirmed using ANOVA (differences in means are significant at the $1 \%$ level). 
Figure 2. Mean sub-criteria scores per level of excellence

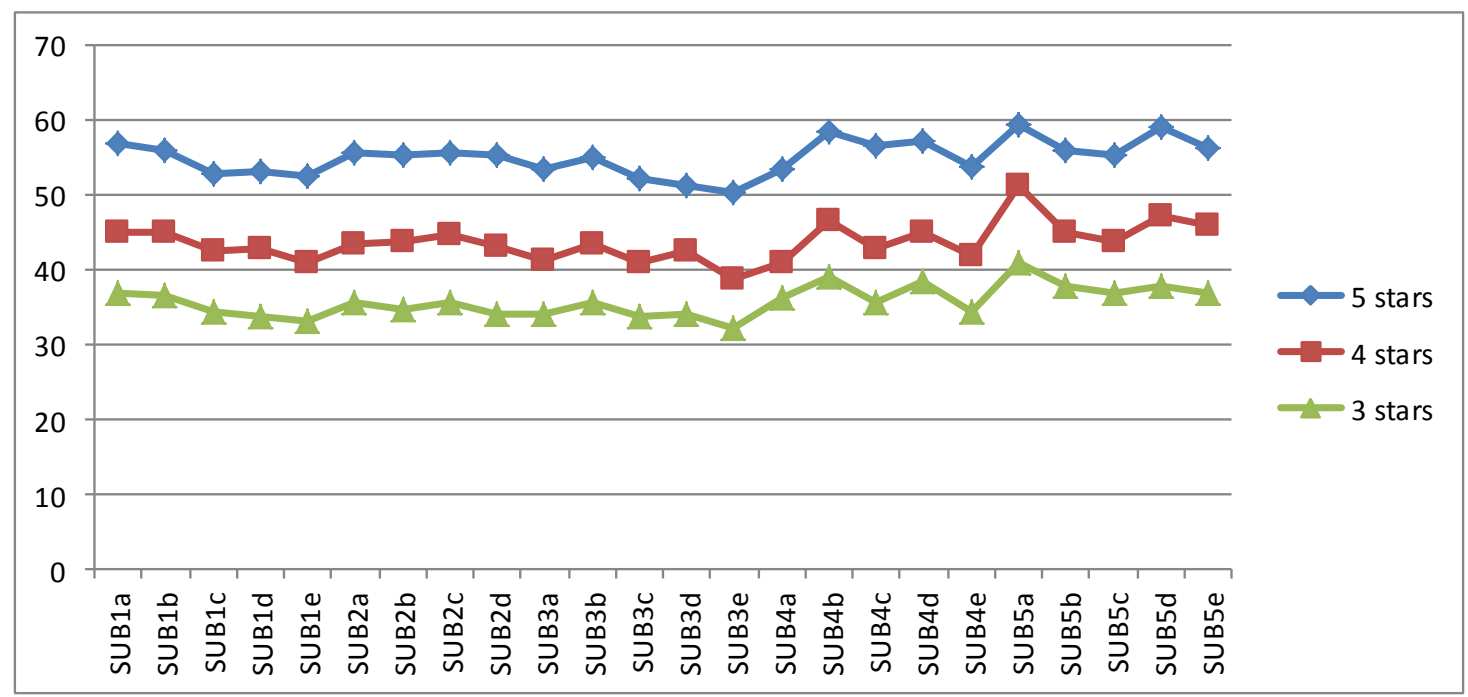

Table 4: Mean scores, standard errors and median scores on sub-criteria per level of excellence

\begin{tabular}{|c|c|c|c|c|c|c|c|c|c|}
\hline \multirow[b]{3}{*}{ Sub-criteria } & \multicolumn{9}{|c|}{ Levels of excellence } \\
\hline & \multicolumn{3}{|c|}{ 5-star } & \multicolumn{3}{|c|}{ 4-star } & \multicolumn{3}{|c|}{ 3-star } \\
\hline & Mean & Std. Error & Median & Mean & Std. Error & Median & Mean & Std. Error & Median \\
\hline SUB1a & 56.81 & 0.73 & 56.25 & 45.09 & 0.60 & 45.00 & 37.03 & 0.76 & 37.50 \\
\hline SUB $1 b$ & 55.85 & 0.68 & 55.00 & 45.15 & 0.57 & 45.00 & 36.54 & 0.70 & 36.67 \\
\hline SUB1c & 52.92 & 0.81 & 52.00 & 42.55 & 0.59 & 42.50 & 34.50 & 0.65 & 35.00 \\
\hline SUB1d & 53.18 & 0.89 & 52.50 & 42.84 & 0.58 & 42.50 & 33.82 & 0.72 & 35.00 \\
\hline SUB1e & 52.65 & 0.98 & 52.50 & 40.83 & 0.64 & 40.00 & 33.05 & 0.76 & 32.50 \\
\hline SUB2a & 55.66 & 0.93 & 55.00 & 43.45 & 0.58 & 44.00 & 35.73 & 0.74 & 35.00 \\
\hline SUB2b & 55.29 & 0.97 & 55.00 & 43.87 & 0.60 & 45.00 & 34.72 & 0.74 & 35.00 \\
\hline SUB2c & 55.76 & 1.15 & 55.00 & 44.58 & 0.67 & 45.00 & 35.60 & 0.84 & 35.42 \\
\hline SUB2d & 55.29 & 0.84 & 55.00 & 43.05 & 0.62 & 42.50 & 33.97 & 0.62 & 35.00 \\
\hline SUB3a & 53.37 & 0.90 & 53.33 & 41.28 & 0.55 & 40.00 & 34.08 & 0.69 & 34.09 \\
\hline SUB3b & 54.94 & 0.88 & 55.00 & 43.37 & 0.63 & 42.50 & 35.59 & 0.74 & 35.00 \\
\hline SUB3c & 52.34 & 0.97 & 52.50 & 40.85 & 0.51 & 40.00 & 33.90 & 0.77 & 35.00 \\
\hline SUB3d & 51.25 & 0.98 & 50.00 & 42.48 & 0.55 & 42.50 & 34.07 & 0.73 & 32.50 \\
\hline SUB3e & 50.41 & 1.03 & 50.33 & 38.65 & 0.57 & 40.00 & 32.33 & 0.78 & 31.67 \\
\hline SUB4a & 53.35 & 1.11 & 52.50 & 40.88 & 0.58 & 40.00 & 36.35 & 0.81 & 35.00 \\
\hline SUB 4b & 58.35 & 1.08 & 58.33 & 46.55 & 0.75 & 47.50 & 38.95 & 0.83 & 38.67 \\
\hline SUB4c & 56.51 & 1.17 & 56.67 & 42.93 & 0.59 & 42.50 & 35.59 & 0.70 & 35.00 \\
\hline SUB4d & 57.28 & 1.23 & 57.50 & 45.13 & 0.62 & 45.00 & 38.35 & 0.72 & 37.50 \\
\hline SUB4e & 53.81 & 0.89 & 53.75 & 41.89 & 0.56 & 42.50 & 34.24 & 0.71 & 35.00 \\
\hline SUB5a & 59.32 & 1.05 & 60.00 & 51.22 & 0.76 & 52.50 & 40.88 & 1.00 & 40.00 \\
\hline SUB5b & 55.93 & 1.09 & 56.67 & 45.12 & 0.69 & 45.00 & 37.85 & 0.79 & 37.50 \\
\hline SUB5c & 55.37 & 0.85 & 55.00 & 43.87 & 0.67 & 45.00 & 36.82 & 0.72 & 37.50 \\
\hline SUB5d & 59.08 & 1.14 & 59.50 & 47.19 & 0.54 & 47.50 & 37.68 & 0.69 & 37.50 \\
\hline SUB5e & 56.32 & 0.74 & 56.25 & 45.81 & 0.57 & 45.00 & 36.78 & 0.68 & 37.50 \\
\hline
\end{tabular}

All differences between groups are statistically significant $(p \leq 0.01)$

As one can observe in Figure 2 and Table 4, all the mean scores of the sub-criteria are between 30 and 60. It is evident that the group of leading organizations has the highest means in all sub-criteria and, similarly, the group of 3-star shows the lowest means. A similar pattern is observed when considering the median scores, and the median test confirms that there are differences in medians between the 3 groups. At first sight, these results are not surprising, as they show that organizations assessed to have different levels of excellence, exhibit significantly different scores with regard to the different enablers sub-criteria.

In spite of the differences between the 3 groups, Figure 2 also indicates that the difference between leading organizations and other organizations is in the magnitude of the average score. Nevertheless, mean scores in sub-criteria follow the same trend in the three 
excellence groups. All recognized for excellence organizations score higher in the same criteria, most noticeably in management of processes (sub-criterion 5a), and their lowest mean scores are also in the same criteria, specially sub-criteria $3 \mathrm{e}$, which is related to people reward and recognition. In general, the distributions of sub-criteria scores did not reject normality and differences between sub-criterion mean and median in each level are negligible. A comparison of variances between levels (ANOVA) indicated that variances are homogeneous, except for the following sub-criteria: $1 \mathrm{~b}$ (leaders monitor improvement of the management system and performance), 3c (empowerment) and $3 \mathrm{~d}$ (communication); post-hoc tests indicated that variances were greater at the lower level. As expected, given that sub-criteria were found to be approximately normally distributed with homogeneous variances, criteria have homogeneous variance. That is, overall assessors are scoring the enablers in a similar way, and there is no indication of different approaches to the best practices in the EFQM, since the same pattern of variation is generally observed. Yet, the few exceptions suggest that the understanding of some people sub-criteria becomes better at higher levels. Furthermore, it appears that leading organizations, as expected from the literature review, are embracing all elements of the framework at a higher level. Nonetheless, the vast majority of organizations that are yet to achieve a high performance do not seem to emphasize a different set of criteria when adopting the model. In short, a consistent structure of the EFQM model is observed within organizations, regardless of their excellence level.

Given that the scores suggest a common approach in the way organizations adopt EFQM enablers instead of different clusters of usages of practices, a one factor model should underlie the data. That is, the correlation in scores would stem from the management approach and way of thinking that the EFQM model provides. In order to confirm these expectations, a common factor in the enablers criteria was estimated using EQS 6 (Bentler, 2006). If a one-factor model fits the correlation of all enablers criteria there would be empirical evidence of a common approach in implementing the best practices embedded in the EFQM enablers. A Confirmatory Factor Analysis (CFA) of the enablers criteria confirms the existence of one factor model (the left side of Table 5 displays the output for this CFA). The goodness of fit indices for the enablers CFA (Satorra-Bentler $\chi^{2}=12.6785 ; 5$ d.f.; $p=0.03$; BB-NNFI=0.981; RMSEA=0.08) were acceptable given the number of manifest variables (criteria) and sample size $(\mathrm{n}=214)$.

Table 5: Criteria loadings in the enablers factor

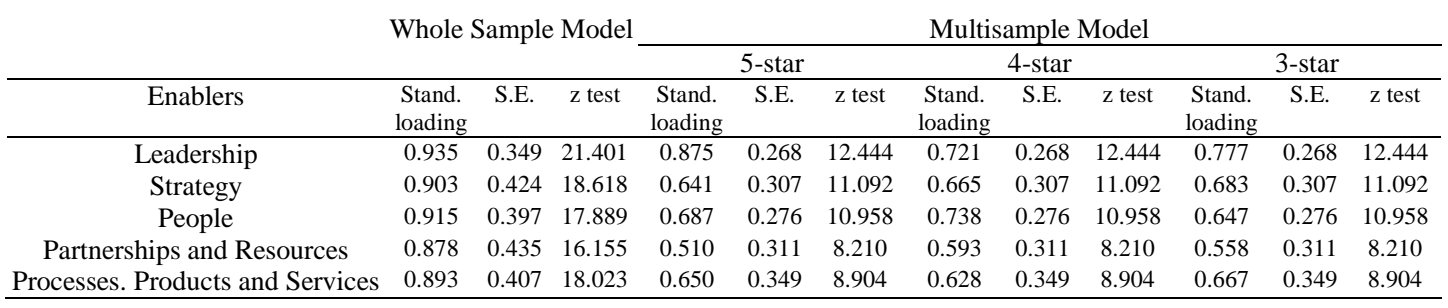

From the standardized loadings it seems as if criteria related to management (leadership and strategy) and people are the most important in explaining enablers excellence. Nevertheless, taking into account the magnitude of the estimated standard errors for the loadings, their 95\% confidence intervals overlap. Therefore, the five enablers criteria are equally important to describe the approach which organizations employ to adopt the best practices embedded in the EFQM model. This means that an equal weighting of all enablers criteria, as established in the EFQM, cannot be rejected. 
Considering the factorial structure of the enablers' domain of the EFQM model, and our previous observations concerning the distributions of scores, it is worth investigating whether the enablers' loadings in the CFA vary with levels of excellence. Following the recommendations by Bentler (2006), a multisample analysis was estimated for the 3 groups (5-star, 4-star and 3-star), constraining factor loadings in the CFA to be equal for the 3 groups. The EQS output for this multisample analysis showed a good fit of the CFA to the data (Satorra-Bentler $\chi^{2}=32.7352 ; 25$ d.f.; $\mathrm{p}=0.138 ;$ BB-NNFI=0.964; RMSEA=0.06). All factor loadings are positive and statistically significant in each group (see the right side of Table 5). According to the multivariate test for all the constraints, as produced by the EQS program, all the constraints are held, since keeping all of them simultaneously does not significantly affect model fit. Consequently, we may conclude that enablers excellence is interpreted in the same way by all accredited organizations, irrespective of the level of excellence attained.

In all, the analyses support the existence of a common approach in the enablers side of the EFQM model, which is in line with previous research (Curkovic et al., 2000; Eskildsen et al., 2001; Prajogo and Brown, 2004; Bou et al., 2009; Jayamaha et al., 2009, 2011) that conceptualized enablers excellence as single constructs in the context of BEMs. Furthermore, leading organizations, compared to the other two subsets, do not use best practices in a different way since a unique approach to the model, as represented by the common factor, is evidenced in all the excellence levels ${ }^{4}$. It is noteworthy that when a factor model of the scores on enablers' sub-criteria was estimated, we observed some correlation between residuals of consecutive sub-criteria, which indicate a pattern of variation in the sub-criteria that is not explained by either the common factor or the EFQM model.

\subsection{Enablers criteria and high performance}

The second Research Question addresses the association between enablers and results. Specifically our aim is to identify which enablers criteria may predict high stakeholdersrelated performance results. The results of the logistic regression analysis are summarized in Table 6, which reports the estimates of the regression coefficients, the standard errors of the coefficients (SE), and goodness-of-fit statistics: pseudo- $\mathrm{R}^{2}$ (Cox \& Snell $\mathrm{R}^{2}$ and Nagelkerke $\mathrm{R}^{2}$ ), Pearson's Chi-square Statistic $\left(\chi^{2}\right)$, the log-likelihood statistic (-2LL), the percentage of cases correctly classified (\% correct); and the significance level of the relationships ( $\mathrm{p}$ values) (Field, 2009). It is noteworthy that, based on Table 2, criteria are correlated, and estimated partial correlations between being a high performer in results and each enablers criterion, controlled for the other enablers criteria, indicated that Leadership and Processes, Product and Services on their own are not associated with high performance. Given the correlation structure, multicollinearity in the regression model that is summarized in Table 6 was assessed. Judging by the Variance Inflation Factors (VIFs) that were less than 6 and thus below the threshold of 10 when sample sizes are large, as well as the estimated tolerances, which were significantly greater than the lower limit of 0.10 , multicollinearity is not a cause for concern in this regression model (e.g. O’brien, 2007; Field, 2009).

\footnotetext{
${ }^{4}$ Following a request from an anonymous referee, a cluster analysis was undertaken which confirmed three homogeneous groups, each one representing different intensity in the use of all the enablers, as ranked by the assessors.
} 
Table 6. Logistic regression: High Performing Organizations

\begin{tabular}{rll}
\hline & b & SE \\
\hline Constant & -23.909 & 4.006 \\
Leadership & -0.053 & 0.084 \\
Strategy & $0.134+$ & 0.074 \\
People & $0.211^{*}$ & 0.089 \\
Partnerships and Resources & 0.085 & 0.069 \\
Processes. Products and Services & 0.107 & 0.070 \\
Size 1 & -0.197 & 0.949 \\
Size 2 & 0.236 & 0.668 \\
Region & 0.551 & 0.669 \\
Membership to CEG & 0.685 & 0.704 \\
Cox \& Snell R & \multicolumn{2}{c}{0.498} \\
Nagelkerke R & \multicolumn{2}{c}{0.739} \\
$\boldsymbol{\chi}^{\mathbf{2}}(\mathbf{d} . \mathbf{f})$. & $147.51(9)^{* *}$ \\
$\mathbf{- 2 L L}$ & \multicolumn{2}{c}{92.058} \\
$\mathbf{\%}$ correct & \multicolumn{2}{c}{$92.1 \%$} \\
\hline
\end{tabular}

Considering the coefficients in Table 6 (b), there is only one significant and positive association at the 5\% level, which relates to the people criterion; hence, organizations with a higher score on people criterion are more likely to perform highly on results. According to this result, in this population of Spanish organizations, the key to achieving high performance in the EFQM lies mainly in aspects of human resource management.

\section{Sensitivity Analysis}

Given that there were only 2 small organizations recognized as 5-star, as shown in Table 3 , the regression model was estimated excluding small organizations. The sample size reduced to 170, and the significance level of the people criterion changed from $5 \%$ to $10 \%$ level $(p$-value $=0.07)$, while the other criteria remained insignificant $(p$-value $>0.10)$. Since the correlation among criteria can have a larger impact as sample sizes decrease, a backward stepwise regression was used, where the controls where kept in the models. In the final model $\left(\right.$ Cox \& Snell $R^{2}=0.513$, Nagelkerke $R^{2}=0.731, \%$ correctly identified $=$ $91.2 \%)$, the estimates indicate that for large and medium organizations, being in the top quartile of the distribution of results is associated with People $(p$-value $=0.049)$ and Strategy ( $\mathrm{p}$-value $=0.027$ ); the controls remain insignificant.

\section{Discussion}

\subsection{Research implications}

\section{Integrated use of best practices}

Concerning the first research question, there is no supporting evidence that a specific combination of best practices may distinguish leading organizations from other organizations that are recognized for excellence. This conclusion is supported by the fact that generally the organizations have similar trends in the scores received per criterion, thus suggesting that the efforts they make towards EFQM sub-criteria are similar, or that excellence in specific sub-criteria is perceived to be equally valued by organizations. Indeed, the findings from the CFA and multisample analysis imply an equal importance of each enabler to explain enablers excellence, irrespective of the level of excellence attained. Some main specific issues are embedded in this general conclusion.

First, regarding how Spanish organizations are actually approaching the adoption of best practices within the EFQM model, this study suggests that leading organizations are 
following an integrated approach, as previously observed in the literature (e.g. García Bernal et al., 2004; Ryan and Moss, 2005). In contrast to previous findings (Ryan and Moss, 2005; Lai et al., 2012), the vast majority of organizations that are yet to achieve the high level of excellence do not exhibit varying patterns of adoption that would suggest that they would be adapting the model according to their preferences or limited resources. In fact, different approaches to the EFQM that would be in line with the patterns that have been observed in the QM literature, as for example those identified by Zhao et al. (2004), are yet to be supported by assessments of Spanish organizations. This finding corroborates Phan et al.'s (2011) observations concerning the use of QM practices in Japanese manufacturing, where QM was approached in a similar fashion by high and low performers. Although there were indications that the variance in enablers is lower for leading organizations, differences in variance for enablers criteria were not statistically significant. In addition, our results from the multisample factorial analysis also reject the view (e.g. Abdullah, 2010) that leading organizations make a more integrated use of the EFQM model than organizations attaining a lower level of excellence. In short, enablers are equally weighted by all.

Spanish organizations appear to be implementing the EFQM model in a holistic manner rather than in a piecemeal fashion. These observations reinforce what is advocated by several authors in the broader QM literature (e.g. Hackman and Wageman, 1995; Powell, 1995; Douglas and Judge, 2001; Martínez et al., 2008; Zu et al., 2010), which posits a need for a fully and rigorous implementation of all QM practices. Moreover, as Douglas and Judge (2001) state "the rhetoric that surrounds it and the mere presence of a QM program are not sufficient for success", contrary, there is a need for a comprehensive QM initiative, which encompasses multiple practices and all elements of QM.

Second, we observed residual correlation between consecutive sub-criteria scores, which would mean that the common factor (the approach) does not fully explain the correlation between certain pairs of consecutive sub-criteria. Some organizations may be placing more emphasis in sub-criteria that they see as more closely related. This fact may be explained by specific features of the EFQM model, as suggested by Jayamaha et al. (2011) and Dahlgaard et al. (2013). The latter study states that despite having a holistic perspective at its conceptual level, the management model underlying the EFQM can break down when the criteria are divided into the 32 sub-criteria. A feature of BEMs is that all sub-criteria are designed to be related to each other. So, during the assessment process, examiners look for alignments between the categories as well as for evidence of an approach that cuts across all sub-criteria (Jayamaha et al. 2011). Hence, it is not surprising that some organizations may want to demonstrate evidences of integration, and such an effort may be responsible for stronger correlation between consecutive subcriteria. An alternative explanation for this slight serial correlation could be that assessors do not independently assess each criterion in the EFQM; they may unwillingly take evaluations on previous criteria into consideration. Hence, this observed residual correlation suggests an unintended consequence, because EFQM was designed to be nonprescriptive and unbiased.

Third, since all recognized for excellence organizations exhibit a consistent approach to the model characterized by the integration of all the enablers criteria, the difference between leading organizations and the other organizations is in the magnitude or degree of use, but not in the relative importance of enablers criteria. That is, the use of the EFQM model appears to follow from a process of development, where an improvement is not represented by new initiatives or practices; rather the same characteristics are in place but with a different degree of adoption. This generally consistent approach to the adoption of 
the model might be explained by the performance path that organizations with 5-star recognition exhibit in the EFQM recognition scheme. In the case of the population in this study, we can refer to the annual Reports of Excellence that are published by CEG and are available online (www.clubexcelencia.org). According to CEG, of those organizations which were awarded 5-star recognition in 2013,67\% had been granted a lower level in previous applications. We can therefore confirm that the EFQM model fits its purpose of providing guidelines for an improvement path, as most organizations show a transition from lower to higher levels of excellence. In addition, CEG's records show that $46 \%$ of organizations rated 5-star in 2013 had been awarded this level of excellence in a previous assessment, thus indicating that good practices are maintained so that high performance can be sustainable. This view supports previous contributions (e.g. Yeung et al., 2003), which concluded that different patterns of adoption of QM practices represent different degrees of QM development.

Fourth, there is a stream of research concerned with national cultures as leverage factors in QM implementation (e.g. Mathews et al. 2001; Vecchi and Brennan, 2009), based on which it could be argued that the Spanish business culture might be linked to the consistent way that the EFQM is adopted in Spain. In this vein and inspired by Mathews et al. (2001), one may reason that the strong uncertainty avoidance dimension of the Spanish national culture could explain why organizations adopt the EFQM as a unique model: by interpreting criteria as rules (or established codes of behavior) that should be followed, they may be trying to minimize the risk of failure. It is noteworthy, however, that to date the literature on the association between QM and national cultures remains inconclusive, as some have stated that QM elements transcend national and cultural boundaries (e.g. Rungtusanatham et al. 2005). Finally, innovation can also be costly, and the data in this study was collected in 2013, when lean initiatives were noticeable in the whole spectrum of the Spanish economy and thus the economic conditions could have acted as another equalizing factor. These are avenues for future research.

Finally, the results support the "commonality logic" stated by Fan and Lu (2014), according to which, all excellent companies have a set of common characteristics and a non-excellent company can become excellent if it acquires them (Fan and Lu, 2014: 480). Contrary to Fan and Lu's (2014) claims, in general, Spanish recognized for excellence organizations seem to benchmark on the best practices of others, but do not customize practices that suit their individual circumstances. Moreover, the present results support the best practice literature, which stresses the importance of archetypes or models of management practices that have been successful in exemplar organizations (Leseure et al., 2004). Consequently, BEMs such as the EFQM model can be used by organizations as guidance to narrow their performance gap.

\section{Institutionalization of the EFQM Excellence Model}

In general, Spanish organizations seem to accept the EFQM as a role model to be adopted as a package, which does not need to be tailored to the organization. As pointed out by Dahlgaard et al. (2013), such a view could be explained by the fact that the structure and language of existing BEMs invite "expert involvement" instead of "employee involvement". Experts and consultants guide the adoption of the model following the same approach to good practices, irrespective of the heterogeneity of resources an organization possesses. Moreover, the external assessment which organizations are subject to when they apply for recognition could act as an equalizing factor. The observed consistency in the adoption of the EFQM model may reflect how institutions such as the CEG or the Excellence Centers (cex), promote the diffusion of the EFQM model and 
rigorously train assessors in the EFQM protocol. As part of the attempt to disseminate good practice, role models are also encouraged, as for example by success stories that are displayed on webpages, brochures and celebrated in events. As previously observed and in line with Wilford's (2007) arguments, when applying for recognition, most organizations will know what the assessors will be looking for. As rational actors, organizations adopt the model with the external assessment in mind, because they want to maximize their likelihood of success. Although the EFQM Model has been designed to be non-prescriptive, the transparency of its assessment and its efforts to encourage good management practices may mean that most organizations interpret the model in a similar fashion.

In conclusion, an imitative process disseminates and legitimizes the EFQM model in Spanish organizations. Institutional theory (DiMaggio and Powell, 1983; Scott, 1987, 1994) rather than a resource based view of the organization seems to better explain the use of the EFQM model in Spain. Accordingly, the diffusion and adoption of best practices and benchmarking may accelerate homogeneity among BEMs adopters. That is, the adoption of BEMs could become isomorphic and the main interest of organizations may be the pursuit of legitimacy (accreditation) in the eyes of important stakeholders.

These considerations are consistent with previous analyses of the adoption of QM initiatives from the institutional perspective, and the expectation that organizations that are recognized for excellence have achieved a certain degree of QM implementation. For instance, Westphal et al. (1997) examined how the early adopters of QM were oriented towards efficiency and tried to customize best practices, whereas new adopters are motivated by institutional forces and legitimacy purposes. More recently, Pinan et al. (2012), in a study of excellence from the perspective of the institutional theory, concluded that organizations applying for recognition are in fact influenced by the way excellent organizations behave.

\section{Discriminating enablers}

The second research question addressed whether specific enablers could make a difference in attaining high stakeholders-related performance results. In those organizations that are recognized for excellence, the people criterion seems to be the differentiator. A similar conclusion was arrived by Merino (2003) while investigating QM practices in the Spanish manufacturing sector. He argued that the importance of HRM practices did not mean that other factors should be ignored, but rather that operational factors were not powerful enough to distinguish between high and low performers. In the Japanese context, Phan et al. (2011) linked superior performance to long-term efforts in human factors. Indeed, the association between HRM and performance has been subject of intense scrutiny in the last two decades, and several findings appear to emphasize the relative importance of the softer dimension of QM in the attainment of high results (e.g. MacDuffie 1995; Powell,1995; Samson and Terziovski, 1999; Birdi et al. 2008) and positive employee outcomes. For example, Birdi et al.'s (2008) longitudinal study of UK manufacturing highlighted the role of job enrichment QM practices in improving performance; more recently, Dahlgaard et al. (2013) also argued that total employee involvement is the most critical success factor in the pursuit of business excellence. Hence, it may not be surprising that the people enabler appears to make a difference for Spanish organizations.

Dow et al. (1999), in a study of manufacturing sites, concluded that only those practices that target workforce commitment, shared vision, and customer focus had a significant positive association with quality outcomes. Into a shared vision, the authors included a 
strategy clearly articulated and communicated and a comprehensive planning process that incorporates stakeholders. Our findings seem to corroborate their analysis, as it was observed that for medium and large recognized organizations in Spain having a strategy is also important to achieve high performance. In fact, this observation may support the idea that as organizations grow the relevance of having a strategy increases in QM.

\subsection{Implication for practitioners}

Organizations applying the EFQM model could benefit from the findings presented in this paper. As a primary objective of a BEM is to distinguish role models organizations, so that others could be inspired by them (Tan, 2002; Lin and Su, 2013), lower performing organizations can take the approach followed by leading companies as a benchmark. Therefore, managers need to focus on a broad orientation in applying the EFQM model, since emphasis on isolated areas is not sufficient for achieving high results. Such an approach is consistent with some other studies of BEMs, including Bou et al. (2005) or Karimi et al. (2014). In addition, managers are reminded that people management practices appear to be directly linked to being a high performing organization. Managers in medium and large organizations should also be attentive to the role that having a tailored, clear and well-monitored strategy may have in the path to high performance. Although our study has made explicit how widespread a comprehensive approach to the EFQM is in Spain, an organization may also achieve high results with a different combination of practices: one of the outliers identified in the population of organizations has attained 5-star recognition with a combination of criteria that emphasizes processes management, establishment and monitoring of targets. We are unable to investigate this outlier further due to shortage of data.

Moreover, organizations need to be aware of what Paauwe and Boselie (2005: 990) warned: "best practices will be copied by competitors as soon as these practices have proven to be successful. The imitative behavior of competing organizations leads to an equilibrium, with no competitive advantage for that specific best practice in the end". According to the authors, managers should try to customize the model as far as they can, but always bearing in mind that the more holistic the adoption of the model, the more successful the organization will be.

This study has also implications for institutions that promote and disseminate the use of the EFQM model in particular, and BEMs in general. Additional insights on criteria weights are also gained, which can inform promoters of BEMs in the process of development and improvement of the models. Overall, there is some support for Eskildsen et al.'s (2001) conclusion that companies do not focus on a cluster of specific enablers criteria when adopting the model, so the EFQM assumption of equal weights can be supported. Finally, there is another observation that promoters of the models should take into account the extra correlation between consecutive sub-criteria that was explained above. This finding can be considered when revising and improving the management model as well as when instructing assessors. Greater attention can be given to clarify the crosscutting issues in the current model and facilitate a horizontal analysis of BEMs.

\subsection{Limitations and future research}

Synergies and nonlinear relationships between enablers criteria and results have not been investigated. Drawing from the QM-performance literature, as for example the early studies of MacDuffie (1995) and Birdi's et al. (2008) indicate, HRM practices may strengthen operational factors of QM. Synergies between enablers are therefore expected 
and would support Merino's (2003) argument that the apparent secondary role of other enablers criteria stem from potential nonlinear relationships. These complex, and possibly nonlinear, relationships can be analyzed in future research where, with larger databases, additional controls and contingent factors can be taken into consideration. Moreover, we were unable to test whether correlations between enablers varied among levels of excellence because of sample sizes in each group. Further analysis in larger databases would shed light on whether leading organizations exhibit a greater correlation between enablers, and hence a greater integration of practices, compared to other organizations.

The study has been based on cross-sectional data including the scores of organizations in the assessment process. This means that a question remains on how the introduction of different types of practices in the enablers criteria may affect results. Future research should analyze the evolution of the scores both in enablers and results in order to identify potential differences in early and last adopters, as suggested by authors as Westphal et al. (1997) or Corredor and Goñi (2011). In terms of scope of study, our research is limited to organizations that have an EFQM Recognition in Spain. Previous studies as McCarthy and Greatbanks (2006) found that there were differences between German and British EFQM-certified organizations. By considering data from organizations being recognized in other countries, one could compare the approach to adopt the model in different institutional and economic settings.

\section{Conclusion}

The purpose of this investigation was to uncover the combination of criteria that characterize leading organizations within the EFQM model in Spain and identify the enablers criteria that may distinguish high performers. The empirical analysis was based on data from the external assessment of organizations in the "Recognized for Excellence" EFQM's scheme. This differs from most previous research since studies generally use data obtained from surveys of company managers.

The present study contributes to the literature examining how to manage the adoption of BEMs. Recognized for excellence organizations in Spain appear to interpret the EFQM model in a similar fashion, indicating that leading organizations may be acting as role models that are followed by most of those which aim to become high performers. Alternatively, organizations that apply for accreditation know what is expected by the assessors and try to fulfill these expectations. Finally, this study contributes to the best practice and QM literature by reinforcing the holistic nature of QM initiatives and the importance of human resource management practices in the attainment of high performance.

\section{Acknowledgements}

The authors appreciate the financial support for this research from the Universitat Jaume I (Ref.P1.1B2013-26), from the Generalitat Valenciana (Ref.AICO/2015/029) and from the Ministerio de Ciencia e Innovación of Spain (Ref.ECO2011-25809). The authors are also greatly indebted to the CEG for providing the data, without its support this study would not have been possible. 


\section{Appendix. The 32 EFQM sub-criteria}

\begin{tabular}{|c|c|}
\hline Sub-criteria & Meaning \\
\hline SUB1a & Leaders develop the Mission, Vision, Values and ethics and act as role models \\
\hline SUB1b & $\begin{array}{l}\text { Leaders define, monitor, review and drive the improvement of the organization's management } \\
\text { system and performance }\end{array}$ \\
\hline SUB1c & Leaders engage with external stakeholders \\
\hline SUB1d & Leaders reinforce a culture of excellence with the organization's people \\
\hline SUB1e & Leaders ensure that organization is flexible and manages change effectively \\
\hline SUB2a & $\begin{array}{l}\text { Strategy is based on understanding the needs and expectations of both stakeholders and the external } \\
\text { environment }\end{array}$ \\
\hline SUB2b & Strategy is based on understanding internal performance and capabilities \\
\hline SUB2c & Strategy and supporting policies are developed, reviewed and updated \\
\hline SUB2d & Strategy and supporting policies are communicated, implemented and monitored \\
\hline SUB3a & People plans support the organization's strategy \\
\hline SUB3b & People's knowledge and capabilities are developed \\
\hline SUB3c & People are aligned, involved and empowered \\
\hline SUB3d & People communicate effectively throughout the organization \\
\hline SUB3e & People are rewarded, recognized and cared for \\
\hline SUB4a & Partners and suppliers are managed for sustainable benefit \\
\hline SUB4b & Finances are managed to secure sustained success \\
\hline SUB4c & Buildings, equipment, materials and natural resources are managed in a sustainable way \\
\hline SUB4d & Technology is managed to support the delivery of strategy \\
\hline SUB4e & $\begin{array}{l}\text { Information and knowledge are managed to support effective decision making and to build the } \\
\text { organization's capability }\end{array}$ \\
\hline SUB5a & Processes are designed and managed to optimize stakeholder value \\
\hline SUB5b & Products and Services are developed to create optimum value for customers \\
\hline SUB5c & Products and Services are effectively promoted and marketed \\
\hline SUB5d & Products and Services are produced, delivered and managed \\
\hline SUB5e & Customer relationships are managed and enhanced \\
\hline SUB6a & Analysis of customer's perceptions of the organization \\
\hline SUB6b & $\begin{array}{l}\text { Analysis of performance indicators: internal measures used by the organization in order to monitor, } \\
\text { understand, predict and improve performance of the organization's external customers }\end{array}$ \\
\hline SUB7a & Analysis of people's perceptions of the organization \\
\hline SUB7b & $\begin{array}{l}\text { Analysis of performance indicators: internal measures used by the organization in order to monitor, } \\
\text { understand, predict and improve the performance of the organization's people }\end{array}$ \\
\hline SUB8a & Analysis of society's perceptions of the organization \\
\hline SUB8b & $\begin{array}{l}\text { Analysis of performance indicators: internal measures used by the organization in order to monitor, } \\
\text { understand, predict and improve performance of the organization's relevant society stakeholders }\end{array}$ \\
\hline SUB9a & $\begin{array}{l}\text { Key strategic outcomes: key financial and non-financial outcomes which demonstrate the success of } \\
\text { the organization's deployment of their strategy }\end{array}$ \\
\hline SUB9b & $\begin{array}{l}\text { Key performance indicators: key financial and non-financial indicators that are used to measure the } \\
\text { organization's operational performance }\end{array}$ \\
\hline
\end{tabular}

\section{References}

Abdullah, A. (2010). Measuring TQM implementation: a case study of Malaysian SMEs. Measuring Business Excellence, 14 (3), 3-15.

Alwazae, M., Kjellin, H., \& Perjons, E. (2014). A synthesized classification system for best practices. VINE: The Journal of Information and Knowledge Management Systems, 44(2), 249-266.

Araújo, M., \& Sampaio, P. (2014). The path to excellence of the Portuguese organisations recognised by the EFQM model. Total Quality Management \& Business Excellence, 25(5-6), 427-438.

Asif, M., \& Gouthier, M. H. (2014). What service excellence can learn from business excellence models. Total Quality Management \& Business Excellence, 25(5-6), 511-531.

Barney, J. (1991). Firm resources and sustained competitive advantage. Journal of Management, 17 (1), 99-120.

Bentler, P.M. (2006). EQS structural equations program manual. Encino, CA: Multivariate Software, Inc. 
Birdi, K., Clegg, C., Patterson, M., Robinson, A., Stride, C.B., Wall, T. D., \& Wood, S.J. (2008). The impact of human resource and operational management practices on company productivity: A longitudinal study. Personnel Psychology, 61(3), 467-501.

Bou, J.C., Escrig, A.B., Roca, V., \& Beltrán, I. (2009). An empirical assessment of the EFQM Excellence Model: Evaluation as a TQM framework relative to the MBNQA Model. Journal of Operations Management, 27(1), 1-22.

Boulter, L., Bendell, T., \& Dahlgaard, J. (2013). Total quality beyond North America: A comparative analysis of the performance of European Excellence Award winners. International Journal of Operations \& Production Management, 33(2), 197-215.

Calvo, A., Picón, A., Ruiz, C., \& Cauzo, L. (2014). The relationships between soft-hard TQM factors and key business results. International Journal of Operations \& Production Management, 34(1), 115143.

Chin, K.S. \& Pun, K.F.(2002). A proposed framework for implementing TQM in Chinese Organizations. International Journal of Quality \& Reliability Management, 19 (3) 272-294

Corbett, L.M., \& Angell, L.C. (2011). Business excellence in New Zealand: Continuous improvement, learning, and change. Total Quality Management \& Business Excellence, 22(7), 755-772.

Corredor, P., \& Goñi, S. (2011). TQM and performance: Is the relationship so obvious? Journal of Business Research, 64, 830-838.

Curkovic, S., Melnyk, S., \& Calantone, R. (2000). Validating the Malcolm Baldrige National Quality Award framework through structural equation modelling. International Journal of Production Research, 38(4), 765-791.

Dahlgaard, J.J., Chen, C.K., Jang, J.Y., Banegas, L.A., \& Dahlgaard-Park, S.M. (2013). Business excellence models: limitations, reflections and further development. Total Quality Management \& Business Excellence, 24(5-6), 519-538.

Dale, B.G. \& Lascelles, D.M. (1997). Total quality management adoption: revisiting the levels. The TQM Magazine, 9 (6), 418-428.

Davies, A. J., \& Kochhar, A. K. (2002). Manufacturing best practice and performance studies: a critique. International Journal of Operations \& Production Management, 22(3), 289-305.

de Menezes L.M., Wood, S., \& Gelade, G. (2010). The integration of operations and human resources management practices and its link with performance: A longitudinal latent class study. Journal of Operations Management, 28, 455-471.

Dimaggio, P.J. \& Powell, W.W. (1983). The iron case revisited, institutional isomorphism and collective rationality in organizational fields. American Sociological Review, 48, 147-160.

Doeleman, H. J., ten Have, S., \& Ahaus, C. T. B. (2014). Empirical evidence on applying the European Foundation for Quality Management Excellence Model, a literature review. Total Quality Management \& Business Excellence, 25(5-6), 439-460.

Douglas, T.J., \& Judge, W.Q. (2001). Total quality management implementation and competitive advantage: the role of structural control and exploration. Academy of Management Journal, 44(1), 158-169.

Dow, D., Samson, D. \& Ford, S. (1999). Exploding the myth: do all quality management practices contribute to superior quality performance? Production and Operations Management, 8, 1-27.

Eskildsen, J. K., Kristensen, K., \& Juhl, H. J. (2004). Private versus public sector excellence. The TQM Magazine, 16 (1), 50-56.

Eskildsen, J.K., Kristensen, K., \& Juhl, H.J. (2001). The criterion weights of the EFQM excellence model. International Journal of Quality \& Reliability Management, 18(8), 783-795.

Eskildsen, J.K., Kristensen, K., \& Juhl, H.J. (2002). Trends in EFQM criterion weights; the case of Denmark 1998-2001. Measuring Business Excellence, 6(2), 22-28.

European Foundation for Quality Management (EFQM) (2012). EFQM Model for Business Excellence. Brussels: EFQM.

Fan, X., \& Lu, D. (2014). Re-balancing the excellence frameworks with individualistic logic. Total Quality Management \& Business Excellence, 25(5-6), 478-493.

Field, A. (2009). Discovering statistics using SPSS. Sage Publications. 
García-Bernal, J., Gargallo-Castel, A., Pastor-Agustín, G., \& Ramírez-Alesón, M. (2004). Total quality management in firms: Evidence from Spain. Quality Management Journal, 11 (3), 20-34.

Gómez, J., Martínez, M., \& Martínez, A.R. (2011). A critical evaluation of the EFQM model. International Journal of Quality \& Reliability Management, 28(5), 484-502.

Grant, R.M. (1991). The resource-based theory of competitive advantage: Implications for strategy formulation. California Management Review, 33(3), 114-134.

Grigg, N., \& Mann, R. (2008). Rewarding excellence: an international study into business excellence award processes. Quality Management Journal, 15(3), 26-40.

Hackman, J.R., \& Wageman, R. (1995). Total quality management: empirical, conceptual, and practical issues. Administrative Science Quarterly, 40 (June), 309-342.

Hayes, R.H., \& Wheelwright, S.C. (1984). Restoring our Competitive Edge. John Wiley.

He, Z., Hill, J., Wang, P., \& Yue, G. (2011). Validation of the theoretical model underlying the Baldrige criteria: Evidence from China. Total Quality Management, 22(2), 243-263.

Hendricks, K.B., \& Singhal, V.R. (2001). Firm characteristics, total quality management, and financial performance. Journal of Operations Management, 19, 269-285.

Heras, I., Arana, G., \& Casadesús, M. (2006). A Delphi study on motivation for ISO 9000 and EFQM. International Journal of Quality \& Reliability Management, 23(7), 807-827.

Heras, I., Marimon, F., \& Casadesús, M. (2012). An empirical study of the relationships within the categories of the EFQM model. Total Quality Management \& Business Excellence, 23(5-6), 523540 .

Jayamaha, N., Grigg, N., \& Mann, R. (2009). A study of the validity of three major business excellence models in the Asia Pacific region. Total Quality Management, 20(11), 1213-1227.

Jayamaha, N., Grigg, N., \& Mann, R. (2011). Empirical analysis of the Baldrige Criteria as both an organizational performance measure and a theoretical model. Measuring Business Excellence, 15(1), 20-33.

Jayaram, J., Ahire, S.L., \& Dreyfus, P. (2010). Contingency relationships of firm size, TQM duration, unionization, and industry context on TQM implementation - A focus on total effects. Journal of Operations Management, 28(4), 345-356.

Kalchschmidt, M. (2012). Best practices in demand forecasting: Tests of universalistic, contingency and configurational theories. International Journal of Production Economics, 140(2), 782-793.

Karimi, A., Safari, H., Hashemi, S. H., \& Kalantar, P. (2014). A study of the Baldrige Award framework using the applicant scoring data. Total Quality Management \& Business Excellence, 25(5-6), 461477.

Lai, K.H., Yeung, A.C., \& Cheng, T.C.E. (2012). Configuring quality management and marketing implementation and the performance implications for industrial marketers. Industrial Marketing Management, 41(8), 1284-1297.

Laugen, B. T., Acur, N., Boer, H., \& Frick, J. (2005). Best manufacturing practices: what do the bestperforming companies do? International Journal of Operations \& Production Management, 25(2), 131-150.

Leseure, M. J., Bauer, J., Birdi, K., Neely, A., \& Denyer, D. (2004). Adoption of promising practices: a systematic review of the evidence. International Journal of Management Reviews, 5(3-4), 169-190.

Lin, C.S., \& Su, C.T. (2013). The Taiwan national quality award and market value of the firms: An empirical study. International Journal of Production Economics, 144 (1), 57-67.

Lu, D., Betts, A., \& Croom, S. (2011). Re-investigating business excellence: Values, measures and a framework. Total Quality Management \& Business Excellence, 22(12), 1263-1276.

MacDuffie, JP. (1995). Human resource bundles and manufacturing performance: Organizational logic and flexible production systems in the world auto industry. Industrial and Labor Relations Review, 48, 197-221.

Mann, R., Adebanjo, D., Laosirihongthong, T., \& Punnakitikashem, P. (2011). Awareness and impact of business excellence in Asia. Total Quality Management \& Business Excellence, 22(11), 1237-1258. 
Martínez, M., Martínez, A.R., \& Choi, T.Y. (2008). Simultaneous consideration of TQM and ISO 9000 on performance and motivation: an empirical study of Spanish companies. International Journal of Production Economics, 113(1), 23-39.

Mathews, B.P., Ueno, A., Kekäle, T., Repka, M., Lopes, Z., \& Silva, G. (2001). European quality management practices: The impact of national culture. International Journal of Quality \& Reliability Management, 18(7), 692-707.

McCarthy, G., \& Greatbanks, R. (2006). Impact of EFQM Excellence Model on leadership in German and UK organisations. International Journal of Quality \& Reliability Management, 23(9), 1068-1091.

Merino, J. (2003). Quality management practices and operational performance: empirical evidence for Spanish industry. International Journal of Production Research, 41(12), 2763-2786.

Meyer, A. D., Tsui, A. S., \& Hinings, C. R. (1993). Configurational approaches to organizational analysis. Academy of Management Journal, 30(6), 1175-1195.

Mohammad, M., Mann, R., Grigg, N., \& Wagner, J. P. (2011). Business Excellence Model: An overarching framework for managing and aligning multiple organisational improvement initiatives. Total Quality Management \& Business Excellence, 22(11), 1213-1236.

Nazemi, J. (2010). A process model for improvement through EFQM. World Applied Sciences Journal, 8 (3), 279-287.

O’brien, R. M. (2007). A caution regarding rules of thumb for variance inflation factors. Quality \& Quantity, 41(5), 673-690.

Paauwe, J., \& Boselie, P. (2005). 'Best practices... in spite of performance': just a matter of imitation? The International Journal of Human Resource Management, 16(6), 987-1003.

Pannirselvam, G.P., \& Ferguson, L.A. (2001). A study of the relationships between the Baldrige categories. International Journal of Quality and Reliability Management, 18(1), 14-34.

Phan, A.C., Abdallah, A.B., \& Matsui, Y. (2011). Quality management practices and competitive performance: Empirical evidence from Japanese manufacturing companies. International Journal of Production Economics, 133(2), 518-529.

Pipan, K. K., Gomišček, B., \& Mayer, J. (2012). Exploratory study of quality and excellence approaches and continuous improvement from the perspective of new institutionalism. Journal for East European Management Studies, 3, 313-332.

Powell, T.C. (1995). Total quality management as competitive advantage: a review and empirical study. Strategic Management Journal, 16, 15-37.

Prajogo, D. I., \& Sohal, A. S. (2004). The multidimensionality of TQM practices in determining quality and innovation performance-an empirical examination. Technovation, 24(6), 443-453.

Prajogo, D.I., \& Brown, A. (2004). The relationship between TQM practices and quality performance and the role of formal TQM programs: An Australian empirical study. Quality Management Journal, 11(4), 31-42.

Prester, J. (2013). Competitive priorities, capabilities and practices of best performers: evidence from GMRG 4 data. Total Quality Management \& Business Excellence, 24(1-2), 138-157.

Psomas, E. L., \& Fotopoulos, C. V. (2010). Total quality management practices and results in food companies. International Journal of Productivity and Performance Management, 59(7), 668-687.

Roca, V., Escrig, A.B., Bou, J.C., \& Beltrán, I. (2006). A systemic and contingent view of the basic elements of quality management. Total Quality Management and Business Excellence, 17(9), 11111127.

Rungtusanatham, M., Forza, C., Koka, B. R., Salvador, F., \& Nie, W. (2005). TQM across multiple countries: convergence hypothesis versus national specificity arguments. Journal of Operations Management, 23(1), 43-63.

Rusjan, B. (2005). Usefulness of the EFQM Excellence model: theoretical explanation of some conceptual and methodological issues. Total Quality Management, 16(6), 363-380.

Ryan, C., \& Moss, S. E. (2005). Total quality management implementation: the "Core" strategy. Academy of Strategic Management Journal, 4, 61-76.

Sadikoglu, E., \& Zehir, C. (2010). Investigating the effects of innovation and employee performance on the relationship between total quality management practices and firm performance: An empirical study of Turkish firms. International Journal of Production Economics, 127(1), 13-26. 
Sampaio, P., Saraiva, P., \& Monteiro, A. (2012). A comparison and usage overview of business excellence models. The TQM Journal, 24(2), 181-200.

Samson, D., \& Terziovski, M. (1999). The relationship between total quality management practices and operational performance. Journal of Operations Management, 17(4), 393-409.

Scott, W.R. (1987). The adolescence of institutional theory. Administrative Science Quarterly, 32, 493-511.

Scott, W.R. (1994). Organizational sociology. London: Aldershot.

Shah, R., \& Ward, P. T. (2003). Lean manufacturing: context, practice bundles, and performance. Journal of Operations Management, 21(2), 129-149.

Short, J. C., Payne, G. T., \& Ketchen, D. J. (2008). Research on organizational configurations: Past accomplishments and future challenges. Journal of Management, 34, 1053-1079.

Sousa, R., \& Voss, C.A. (2002). Quality management re-visited: a reflective review and agenda for future research. Journal of Operations Management, 20, 91-109.

Talwar, B. (2011). Business excellence models and the path ahead. The TQM Journal, 23(1), 21-35.

Tan, K.C. (2002). A comparative study of 16 national quality awards. The TQM Magazine, 14 (3), 165171.

Vecchi, A., \& Brennan, L. (2009). Quality management: a cross-cultural perspective. Cross Cultural Management: An International Journal, 16(2), 149-164.

Voss, C. A. (1995). Alternative paradigms for manufacturing strategy. International Journal of Operations \& Production Management, 15(4), 5-16.

Voss, C. A. (2005). Paradigms of manufacturing strategy re-visited. International Journal of Operations \& Production Management, 25(12), 1223-1227.

Westphal, J. D., Gulati, R., \& Shortell, S. M. (1997). Customization or conformity? An institutional and network perspective on the content and consequences of TQM adoption. Administrative Science Quarterly, 42 (2), 366-394.

Wilford, S. (2007). The limits of award incentives: The (non-) relationship between awards for quality and organisational performance. Total Quality Management \& Business Excellence, 18(3), 333-349.

Williams, R., Bertsch, B., Van der Wiele, A., Van Iwaarden, J., \& Dale, B. (2006). Self-Assessment against Business Excellence Models: A Critique and Perspective. Total Quality Management and Business Excellence, 17(10), 1287-1300.

Wu, S.J., \& Zhang, D. (2013). Analyzing the effectiveness of quality management practices in China. International Journal of Production Economics, 144, 281-289.

$\mathrm{Xu}$, Y., \& Yeh, C. H. (2012). An integrated approach to evaluation and planning of best practices. Omega, 40(1), 65-78.

Yeung, A.C.L., Chan, L.Y., \& Lee, T.S. (2003). An empirical taxonomy for quality management systems: a study of the Hong Kong electronics industry. Journal of Operations Management, 21(1), 45-62.

Zairi, M., \& Alsughayir, A.A. (2011). The adoption of excellence models through cultural and social adaptations: An empirical study of critical success factors and a proposed model. Total Quality Management \& Business Excellence, 22(6), 621-654.

Zhao, X., Yeung, A.C., \& Lee, T.S. (2004). Quality management and organizational context in selected service industries of China. Journal of Operations Management, 22(6), 575-587.

Zu, X., Robbins, T.L., \& Fredendall, L.D. (2010). Mapping the critical links between organizational culture and TQM/Six Sigma practices. International Journal of Production Economics, 123(1), 86-106. 